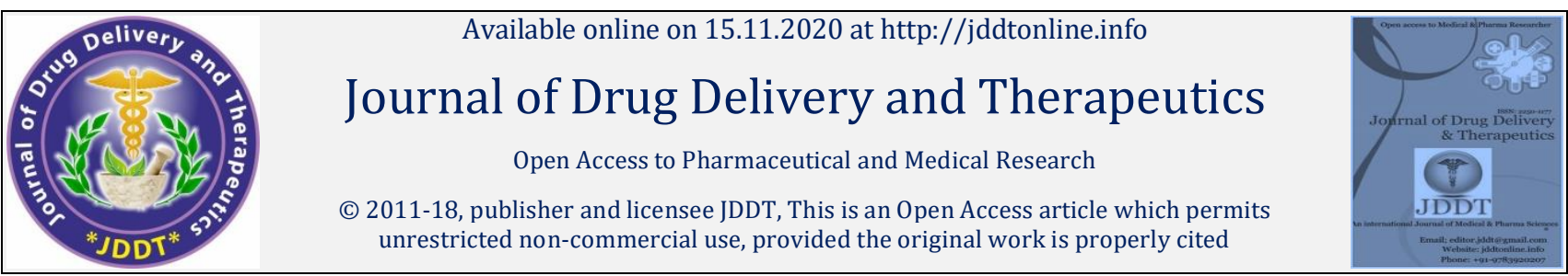

Open $\odot$ Access

\title{
Transmission and Pathogenesis of Coronavirus Disease (COVID-19) Outbreak
}

\author{
Yousef Sawikr ${ }^{*}$, Mohamed R Algetani² \\ ${ }^{1}$ Department of Pharmacology and Toxicology, Faculty of Medicine University of Ajdabiya, Libya \\ ${ }^{2}$ Department of Botany, University of Benghazi, Libya
}

\begin{abstract}
The current pandemic of coronavirus disease 2019 (COVID-19) caused by severe acute respiratory syndrome coronavirus 2 (SARS-CoV-2) has presented unmatched challenges to the healthcare systems in almost every country around the world. Currently, there are no established effective vaccines or therapeutic agents against the virus. Present clinical management includes infection prevention and control process and supportive care including supplemental oxygen and mechanical ventilator support. It is proposed this is likely the zoonotic beginning of COVID19. Individual to-individual transmission of COVID-19 contamination prompted the separation of patients that were accordingly managed an assortment of medicines.
\end{abstract}

Keywords: COVID-19, SARS-CoV-2, supplemental oxygen, ventilator support

Article Info: Received 11 Sep 2020; $\quad$ Review Completed 27 Oct 2020; $\quad$ Accepted 06 Nov 2020; $\quad$ Available online 15 Nov 2020

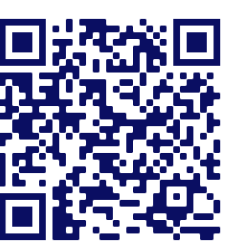

Cite this article as:

Sawikr Y, Algetani MR, Transmission and Pathogenesis of Coronavirus Disease (COVID-19) Outbreak, Journal of Drug Delivery and Therapeutics. 2020; 10(6):239-241 http://dx.doi.org/10.22270/jddt.v10i6.4577

*Address for Correspondence:

Dr Yousef Sawikr, PhD, Department of Pharmacology and Toxicology, Faculty of Medicine, University of Ajdabiya, Libya

\section{PROPERTIES OF SARS-CoV-2}

Coronaviruses are enveloped viruses with a notable experience unmarried-stranded RNA genome (26 to $32 \mathrm{~kb})^{1}$. Coronaviruses are members of the subfamily Coronavirinae from the own family Coronaviridae and the order Nidovirales. based totally on phylogenetic relationships and genomic systems, the subfamily Coronavirinae is break up into four genera - Alphacoronavirus, Betacoronavirus, Gammacoronavirus, and Deltacoronavirus. Alphacoronaviruses and beta coronaviruses only infect mammals. Gammacoronaviruses and deltacoronaviruses infect birds and on occasion even infect mammals along with rodents and bats. Gammacoronaviruses and Betacoronaviruses are diagnosed to purpose respiratory ailments in human beings and gastroenteritis in animals ${ }^{2}$. A coronavirus particle consists of four structural proteins: the nucleocapsid, envelope, membrane, and spike (three). The Spike (S) protein office work club-fashioned protrusions that stick out all over the virion, similar to a crown or the solar's corona, for that reason, the call. These protrusions bind to receptors on host cells thus decide the mobile kinds and the form of species that the virus can infect this structure may prompt mistakes, cause fast transformation ${ }^{3}$. A portion of these changes can give the infection new properties, for example, the capacity to contaminate new cell types or even new species that can create genuine lung disease ${ }^{4}$ the spike protein assume significant function for the objective of immunization, remedial and determination. 


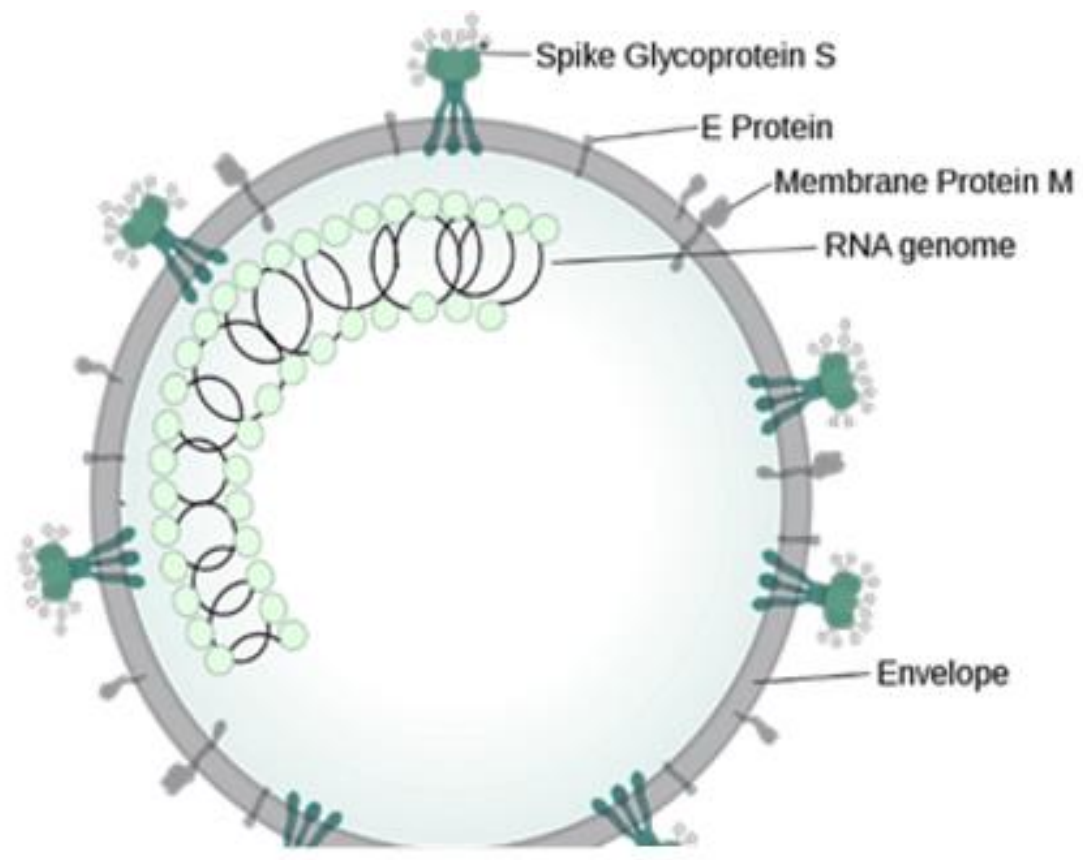

Figure1: Diagrammatic representation of the structure of novel corona virus

\section{APPROACH OF TRANSMISSION}

COVID-19 has the potential to spread thru respiration droplets at some point of near touch due to its predominance within the upper respiratory tract. It's far possible to gather COVID-19 while in close proximity to an inflamed character who coughs, sneezes, or maybe talks. Following the initial publicity, it could take in to fourteen days earlier than a man or woman develops signs and symptoms. The median time from publicity to symptom onset has been reported to be four to five days (CDC, 2020). Additionally, over $80 \%$ of inflamed people are asymptomatic or have moderate signs (Wu et al., 2020). ${ }^{5}$

The fundamental courses of individual to-individual transmission of respiratory infections are the accompanying:

a) The immediate or circuitous contact with a contaminated subject;

b) The enormous beads produced by hacking/sniffling that can arrive at a uninfected subject.

c) The inward breath of little airborne particles staying in the air 6 .

According to the last mentioned, 7 have unequivocally proposed that the SARS-CoV-2 has been spreading through the air in this equivalent line.

Consistent with cutting-edge evidence, the COVID-19 virus is typically transmitted between human beings through respiration droplets and call routes 8 . The droplets can unfold as much as 7-8 meters beneath beneficial environmental situations, which include humidity and temperature, the gasoline cloud and its payload of pathogen 9. Transmission may additionally arise through fomites within the immediately surroundings across the infected person 10. Therefore, the transmission of the COVID-19 virus can arise by way of direct contact with inflamed people and indirect touch with surfaces in the immediate environment or with objects used on the infected man or woman.

Asymptomatic and pre-indicative people are able to do accidentally dispersion the infection, despite the fact that the danger of spread is the most extreme in suggestive patients because of viral movement (CDC, 2020). As most of gentle or indicative cases regularly go unreported, it is hard for networks to contain high danger territories. Running rules have suggested intermittent hand washing, evasion of direct contact, just as stay-at-home and physical separating requests to help moderate the spread of the infection.

\section{PATHOGENESIS OF COVID-19}

Patients with COVID-19 show clinical manifestations including fever, nonproductive cough, dyspnea, myalgia, fatigue, normal or decreased leukocyte counts, and radiographic evidence of pneumonia 11 Hence, although the pathogenesis of COVID-19 is poorly understood, the similar mechanisms of SARSCoV and MERS-CoV still can give us a lot of information on the pathogenesis of SARS-CoV-2 infection to facilitate our recognition of COVID-19.

Considerate the mechanism of pathogenesis of SARS-CoV-2 permits researchers to become aware of goals for novel therapeutic dealers to prevent or treat the disorder. SARS$\mathrm{CoV}-2$ is an unmarried stranded RNA-enveloped virus $\mathbf{1 2}$. Mechanisms dependent on a spike -s-protein contact with host cellular equation is s-protein priming interact with host cellular receptor in to be had of host cellular proteases fundamental target is human lung epithelial cells 13 he accurate mechanism of lung involvement is unsure: assumed mechanisms include sepsis leading to cytokine hurricane syndrome or direct cellular harm because of the virus.

Cytokine storm associated with COVID-19 pneumonia has been accompanied by way of stronger serum stages of interleukin-1 $\beta$ (IL-1 $\beta)$, IL-2, IL- 7, IL-8, IL-nine, IL-5, interferon- $\gamma$, tumor necrosis thing alpha (TNF- $\alpha$ ), G-CSF (granulocyte colonystimulating factor) and GM-CSF (granulocytemacrophage colony-stimulating thing) that resulted in an inflammatory response and finally tissue damages along with pulmonary edema ${ }^{14}$. Therefore, AKI at this situation can be a end result of frame infection, extended vascular permeability, extent depletion and cardiomyopathy which could lead to cardio-renal reaction 15. additionally, these mediators might exert dangerous effect on renal tissue thru induction of surprise, rhabdomyolysis following tissue hypoxia, and an accelerated stage of CPK in sufferers 
admitted to ICU 16, 17, 18 This syndrome consists of systemic endothelial damage which makes pleural effusion, edema, intra-abdominal hypertension, third area fluid loss, intravascular fluid depletion and hypotension

\section{CONCLUSIONS}

The modern COVID-19 pandemic is absolutely a global public health problem. COVID-19 is a brand new disorder resulting from the new pressure of coronavirus, SARS-CoV-2. There is no evidence to endorse any specific antiCOVID-19 treatment there are no antiviral drugs proven to be powerful now. Ongoing research continues to analyze the protection and efficacy of repurposed pills, at the same time as SARS$\mathrm{CoV}-2$ vaccine trials are rapidly underway.

Conflict of interests: No conflict of interests is declared.

\section{REFERENCES}

1. Su S, Wong G, Shi W, Liu J, Lai A, Zhou J, et al. Epidemiology, genetic recombination, and pathogenesis of coronaviruses. Elsevier [Internet]. [cited 2020 Sep 4]; Available from: https://www.sciencedirect.com/science/article/pii/S0966842 $\mathrm{X} 16000718$

2. Wu R, Wang L, Kuo H, Shannar A, ... RP-CP, 2020 undefined. An update on current therapeutic drugs treating COVID-19. Springer [Internet]. [cited 2020 Aug 25]; Available from: https://link.springer.com/content/pdf/10.1007/s40495-02000216-7.pdf

3. Schoeman D, Fielding BC. Coronavirus envelope protein: Current knowledge. Vol. 16, Virology Journal. BioMed Central Ltd.; 2019.

4. Weiss SR, Navas-Martin S. Coronavirus Pathogenesis and the Emerging Pathogen Severe Acute Respiratory Syndrome Coronavirus. Microbiol Mol Biol Rev [Internet]. 2005 [cited 2020 Sep 5]; 69(4):635-64. Available from: http://mmbr.asm.org/

5. An update on current therapeutic drugs treating COVID-19. Springer [Internet]. [cited 2020 Sep 5]; Available from: https://link.springer.com/content/pdf/10.1007/s40495-02000216-7.pdf

6. Eissenberg T, Kanj SS, Shihadeh AL. Treat COVID-19 as Though It Is Airborne: It May Be. AANA journal. NLM (Medline); 2020; 88:29-30.

7. Morawska L, International JC-E, 2020 undefined. Airborne transmission of SARS-CoV-2: The world should face the reality. Elsevier [Internet]. [cited 2020 Sep 5]; Available from: https://www.sciencedirect.com/science/article/pii/S0160412 $02031254 \mathrm{X}$

8. Liu J, Liao X, Qian S, Yuan J, Wang F, Liu Y, et al. Community Transmission of SARS-CoV-2. 2020 [cited 2020 Sep 6]; Available from: https://doi.org/10.1016/S0140-6736

9. Jama LB-, 2020 undefined. Turbulent gas clouds and respiratory pathogen emissions: potential implications for reducing transmission of COVID-19. jamanetwork.com [Internet]. [cited 2020 Sep 6]; Available from: https://jamanetwork.com/journals/jama/articleabstract/2763852

10. Ong S, Tan Y, Chia P, Lee T, Jama ON-, 2020 undefined. Air, surface environmental, and personal protective equipment contamination by severe acute respiratory syndrome coronavirus 2 (SARS-CoV-2) from a symptomatic. jamanetwork.com [Internet]. [cited 2020 Sep 6]; Available from: https://jamanetwork.com/journals/jama/articleabstract/2762692

11. Huang C, Wang Y, Li X, Ren L, Zhao J, Hu Y, et al. Clinical features of patients infected with 2019 novel coronavirus in Wuhan, China. Lancet [Internet]. 2020 Feb [cited 2020 Sep 6];395(10223):497-506. Available from: https://linkinghub.elsevier.com/retrieve/pii/S0140673620301 835

12. Sanders J, Monogue M, Jodlowski T, Jama JC-, 2020 undefined. Pharmacologic treatments for coronavirus disease 2019 (COVID-19): a review. jamanetwork.com [Internet]. [cited 2020 Aug 25]; Available from: https://jamanetwork.com/journals/jama/articleabstract/2764727

13. Rothan $\mathrm{H}$, autoimmunity SB-J of, 2020 undefined. The epidemiology and pathogenesis of coronavirus disease (COVID19) outbreak. Elsevier [Internet]. [cited 2020 Sep 6]; Available from: https://www.sciencedirect.com/science/article/pii/S0896841 120300469

14. Huang C, Wang Y, Li X, Ren L, Zhao J, Hu Y, et al. Clinical features of patients infected with 2019 novel coronavirus in Wuhan, China. Elsevier [Internet]. [cited 2020 Aug 24]; Available from: https://www.sciencedirect.com/science/article/pii/S0140673 620301835

15. Ronco C, Nephrology TR-NR, 2020 undefined. Kidney involvement in COVID-19 and rationale for extracorporeal therapies. nature.com [Internet]. [cited 2020 Aug 24]; Available from: https://www.nature.com/articles/s41581-020-0284-7

16. Bai Y, Yao L, Wei T, Tian F, Jin D, Chen L, et al. Presumed asymptomatic carrier transmission of COVID-19. jamanetwork.com [Internet]. [cited 2020 Aug 24]; Available from: https://jamanetwork.com/journals/jama/articleabstract/2762028

17. Cheng $Y$, Luo $R$, Wang $K$, Zhang $M$, Wang Z, international LD-K, et al. Kidney disease is associated with in-hospital death of patients with COVID-19. Elsevier [Internet]. [cited 2020 Aug 24]; Available from: https://www.sciencedirect.com/science/article/pii/S0085253 820302556

18. Kumar A, Zarychanski R, Pinto R, Cook D, Jama JM-, 2009 undefined. Critically ill patients with 2009 influenza A (H1N1) infection in Canada. jamanetwork.com [Internet]. [cited 2020 Aug 24]; Available from: https://jamanetwork.com/journals/jama/articleabstract/184799 